\section{Sequence Characterization of matrix protein (M1) in influenza $A$ viruses (H1, H3 and H5)}

\author{
Jun Zhang, ${ }^{1}$ Xiao Ling Yu, ${ }^{1}$ Lei Xu, ${ }^{1}$ \\ Fang Zhi Li, ${ }^{1}$ Yong Gang Li ${ }^{2}$ \\ 'Department of Respiratory Diseases, \\ The Forth Hospital affiliated to China \\ Medical University. China; \\ 2Department of Virology, Research \\ Institute for Microbial Diseases, Osaka \\ University, Japan
}

\begin{abstract}
This study brings the analysis of amino acid sequences of matrix protein (M1) from the influenza virus A (H1N1, H3N2 and H5N1) during 2007-2208. 741 sequences of M1 were compared, of them, H1N1 388; H3N2 251 and H5N1 102. Even though, the M1 is relatively conserved among the influenza A viruses, we found some variations in the Ml among the viruses, H1N1, H3N2 and H5N1. The nuclear localization signal at amino acid 101 to 105 is RKLKR for H1N1 and H3N2, but for H5N1 is KKLKR. All differences of amino acid in M1 of $\mathrm{H} 1, \mathrm{H} 3$ and $\mathrm{H} 5$ were listed. 80 sequences of $\mathrm{M} 1$ of H1N1 H3N2 and H5N1 were used for phylogenetic analysis. There is no reasontantment found in the M1 among these subtypes. Further study is needed to study the differences of the function of M1 among H1N1, H3N2 and H5N1. The M1 of H5N1 may contribute to the high pathogenesis to this virus.
\end{abstract}

\section{Introduction}

Influenza virus belongs to the family Orthomyxoviridae and possesses a genome of eight single-stranded negative-sense viral RNA that encodes a total of 10 proteins. ${ }^{1}$ The membrane protein $(\mathrm{M})$ gene of influenza $\mathrm{A}$ viruses is 1027 nucleotides long and encodes two proteins, M1 and M2, derived by splicing of mRNA. ${ }^{2} \mathrm{M} 1$ is a matrix protein that lies just beneath the viral envelope in the form of dimmers and interact with viral ribonucleoprotein(vRNP). M1 is a relatively small, highly conserved protein, 252 amino acids in type A and 248 amino acid in type B viruses. ${ }^{3}$ The M1 protein harbors an $\mathrm{N}$-terminal $(\mathrm{N})$ domain (aa 2-67), a middle (M) domain (aa 91-158) and C-terminal (C) domain (aa165-252). ${ }^{4}$ The nuclear location signal (NLS) 95KAVKLYRKLKR105 is in M domain and C-terminal domain has affinity for RNP.,6 M1 is most abundant protein in virus particle and plays critical roles in many aspects of virus replication. During early viral replication, newly synthesized M1 is transported from its cytoplasmic translation site into the nucleus ${ }^{7}$ vial a nuclear localization signal in M1.5,8 Later in the replication cycle, accumulation of M1 occurs in the cytoplasm coincident with the export of RNPs from the nucleus ${ }^{9-13}$ the binding of RNA, nucleoprotein (NP), and M1 is required for the maturation and transport of M1/RNP complex from the nucleus to the cytoplasm. ${ }^{14,15}$ M1 prevents RNP from reentering the nucleus ${ }^{13}$ and M1 also bind to NS2 ${ }^{16,17}$ to facilitate nuclear export of the viral $\mathrm{RNP}^{18}$ in the cytoplasm. M1 interacts with HA, NA, M2 and lipid membrane during budding of new virions form the cell surface. ${ }^{19-25}$ on the other
Correspondence: Yong Gang Li, Department of Virology, Research Institute for Microbial Diseases, Osaka University, Japan.

Tel. +81.6.6879.8309 - Fax: +81.6.6879.8310.

E-mail: yonggang@biken.osaka-u.ac.jp

Key words: influenza virus A, H1N1, H3N2, H5N1, matrix protein (M1).

Received for publication: 25 May 2011.

Accepted for publication: 2 September 2011.

This work is licensed under a Creative Commons Attribution NonCommercial 3.0 License (CC BYNC 3.0).

(C) Copyright J. Zhang et al., 2011

Licensee PAGEPress, Italy

Microbiology Research 2011; 2:e16

doi:10.4081/mr.2011.e16

hand, virus budding does not occur in the absence of M1, and M1 expressed along can form virus-like particles in transfected cells. ${ }^{26}$ Also, Heat shock cognate protein 70 (Hsc70) as a M1 binding protein, the C-terminal domain of M1 interacts with Hsc70. Hsc70 is directly associated with $\mathrm{M} 1$, is required for viral production. ${ }^{27}$

In this paper, we analysis the M1 sequences from the viruses of H1N1, H3N2 and H5N1 downloaded from the gene bank. Even though, M1 is relatively conserved among the viruses, but we have found the variation of $\mathrm{M} 1$ among the viruses, H1N1, H3N2 and H5N1. The differences may contribute to the phenotype of these viruses, H1N1, H3N2 and H5N1. Further study is needed to clarify the different functions of M1 of $\mathrm{H} 1 \mathrm{~N} 1, \mathrm{H} 3 \mathrm{~N} 2$ and H5N1.
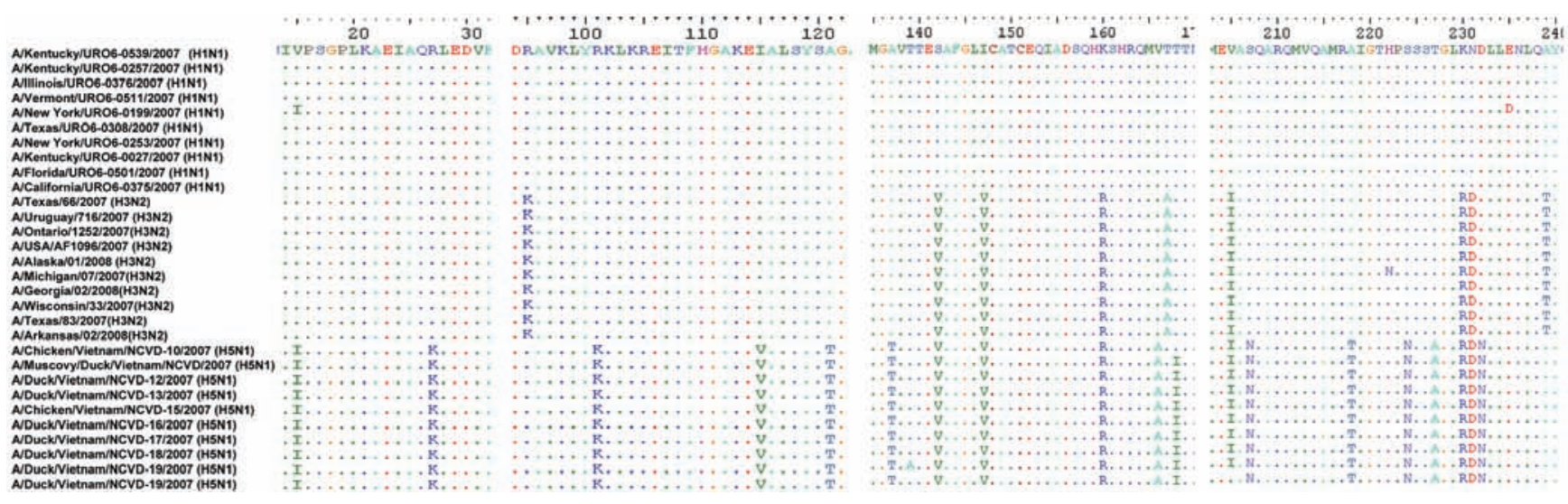

Figure 1. Comparison of amino acid sequences of $\mathrm{M} 1$ of the $\mathrm{H} 1 \mathrm{~N} 1, \mathrm{H} 3 \mathrm{~N} 2$ and $\mathrm{H} 5 \mathrm{~N} 1$ influenza virus isolates. Dots indicate residues identical to the A/Kentucky/UR06-0539/2007. 
Table 1. Amino acid differences in M1 among H1N1, H3N2 and H5N1.

\begin{tabular}{cccccccccccccccccccccc}
\hline Virus & 95 & 101 & 115 & 121 & 137 & 142 & 147 & 160 & 166 & 167 & 168 & 205 & 207 & 218 & 224 & 227 & 230 & 231 & 232 & 239 \\
H1N1 & R & R & I & A & A & S & I & K & V & T & T & V & S & A & S & T & K & N & D & A \\
\hline H3N2 & K & R & I & A & A & V & V & R & V & A & T & I & S & A & S & T & R & D & D & T \\
H5N1 & R & K & V & T & T & V & V & R & A & T & I & I & N & T & N & A & R & D & N & A \\
\hline
\end{tabular}

\section{Materials and Methods}

741 of the amino acid sequences of the influenza type A (H1N1, H3N2 and H5N1) M1 were downloaded from Gene Bank, of them, H1N1, 388; H3N2, 251 and H5N1, 102. Multiple amino acid sequence alignment was performed on the prepared set of 3 different subtypes of M1 using the program Bioedit. The phylip format tree output was applied using the bootstrappong procedure; the number of bootstrap trials used was 1000 . The tree was drawn with program Tree View.

\section{Results and Discussion}

Amino acid sequences of M1 of H1N1, H3N2 and H5N1 have been compared. As shown in Figure 1 and Table 1. The domain of the nuclear localization signal of M1, containing the basic amino acids 101RKLKR105 can bind viral RNA, ${ }^{28-31}$ NS2 protein, ${ }^{32}$ and NP during maturation and preparation of RNPs for export to the cytoplasmic compartment. ${ }^{33}$ The basic amino acids of basic region in $\mathrm{H} 5 \mathrm{~N} 1$ are different from that in H1N1 and H3N2, in H1N1 and H3N2 is 101RKLKR105, but in H5N1 is 101KKLKR105. Hui reported that if R101 changed into A101, the mutant virus yield a lower PFU titer and a smaller plaque size. There is still no report on how about K101 in M1 of H5N1 effects the virus replication. ${ }^{34}$ The differences of amino acid of M1 of H1N1, H3N2 and H5N1 have been outlined in Table 1. M1 of H5N1 may have different function from that of H1N1 and H3N2, because a single amino acid change in M1 was shown to be responsible for the higher yield in mouse lungs. ${ }^{3,} 35-38$ Fan reported that two amino acid residues in the matrix protein M1 contribute to the virulence difference of $\mathrm{H} 5 \mathrm{~N} 1$ avian influenza viruses in mice. $^{39}$ The different amino acid of M1 of H1N1, H3N2 and H5N1 may contribute to the different function of M1. In Figure 2, the polygenetic tree showed that there is no reassortment of M1 happened among subtypes, H1, H3 and $\mathrm{H} 5$, although reassortment of human influenza A viruses between the same subtype has occurred frequently. ${ }^{40,41}$ So, the M1 is highly conserved and no reassortment among subtypes. On the other hand, It is possible that $\mathrm{M}$ gene determines that host range through

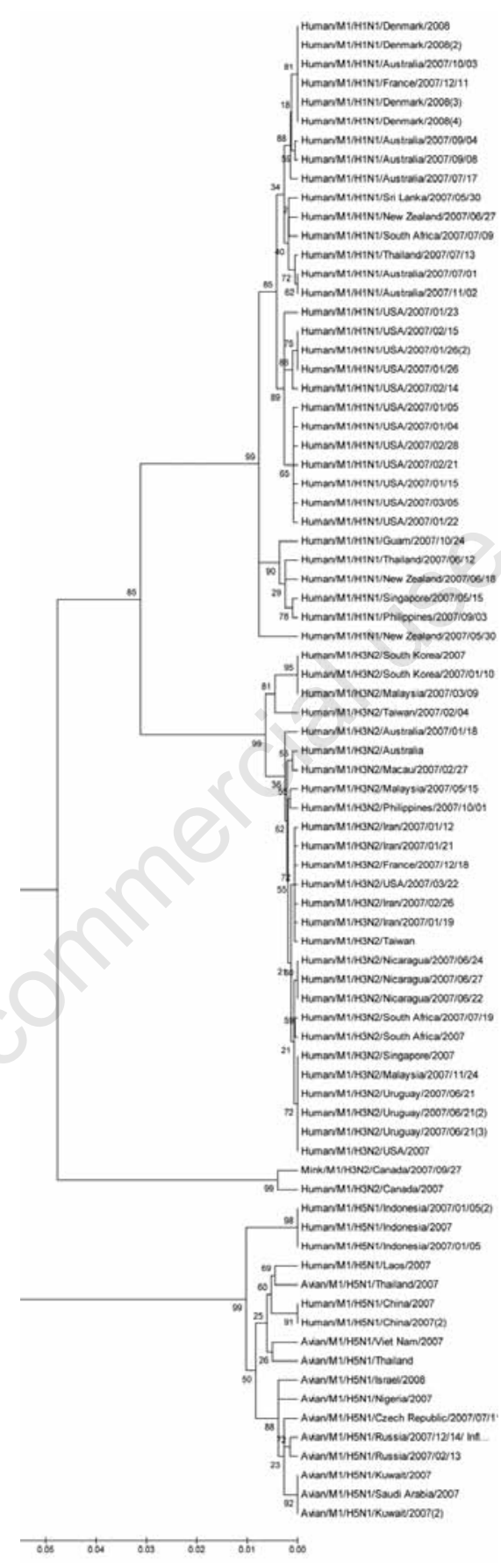

Figure 2. The polygenetic trees of M1 of $\mathrm{H1}, \mathrm{H} 3$ and H5. Polygenetic trees were from nucleotide sequences by the neighbor-joining method. The scale bar indicates 0.01 nucleotide changes per site. Numbers at the nodes indicate confidence levels of a bootstrap analysis with $\mathbf{1 . 0 0 0}$ replications as a percentage value. the interaction between M1 and vRNPs. ${ }^{42-44}$ In addition, many studies have shown the interaction between M1 protein and host proteins, such as RACK1, MAPK, and core histone. ${ }^{45-48}$ The further study is needed to clarify the differences of M1 function among subtypes.

\section{References}

1. Palese P, Shaw ML. Orthomyxoviridae: the viruses and their replication. In: Knipe DM, Griffin PE, Lamb RA, Roizman MB, Straus SE, eds. Fields virology, 5th ed. Philadelphia , PA: Lippincott Williams and Wilkins; 2006.

2. Lamb RA. The genes and proteins of the influenza viruses p1-87. In: Krug RM, editor. The influenza viruses. New York, NY: Plenum Press; 1989.

3. MuCullers JA, Hoffmann E, Huver VC, Nickerson AD. A single amino acid change in the C-terminal domain of the matrix protein M1 of influenza B virus confers mouse adaptation and virulence. Virology 2005;336:318-26.

4. Sha B, Luo M. Structure of a bifunctional membrane-RNA binding protein, influenza virus matrix protein M1. Nat Struct Mol Biol 1997;4:239-44.

5. Ye Z, Robinson D, Wagner RR. Nucleustargeting domain of the matrix protein (M1) of influenza virus. J Virol 1995;69: 1964-70.

6. Baudin F, Petit I, Weissenhorn W, Ruigrok RWH. In vitro dissection of the membrane and RNP binding activities of influenza virus M1 protein. Virology 2001;281:102-8.

7. Rey 0, Nayak DP. Nuclear retention of M1 protein in a temperature-sensitive mutant of influenza (AWSN/33) virus does not affect nuclear export of viral ribonucleoproteins. J Virol 1992;66:5815-24.

8. Ye Z, Baylor NW, Wagner RR. Transcription-inhibition and RNA-binding domains of influenza virus matrix protein mapped with antiidiotype antibodies and synthetic peptides. J. Virol 1989;63:3586-94.

9. Bui M, Whittaker GR, Helenius A. Effect of $\mathrm{M} 1$ protein and low $\mathrm{pH}$ on nuclear transport of influenza virus ribonucleoproteins. J Virol 1996;70:8391-401.

10. Bui M, Wills EG, Helenius A, Whittaker GR. Role of the influenza virus M1 protein in 
nuclear export of viral ribonucleoproteins. J Virol 2000;74:1781-6.

11. Herz C, Stavnezer E, Krug RM. Influenza virus, an RNA virus, synthesizes its messenger RNA in the nucleus of influenza cells. Cell 1981;26:391-400.

12. Krug RM, Alonso-Coplen RV, Julkumen L, Katze MG. Expression and replication of the influenza virus genome, p. 89-162. In: Krug RM, editor. The influenza viruses. New York, NY: Plenum Press; 1989.

13. Martin K, Helenius A. Nuclear transport of influenza virus ribonucleoproteins: the viral matrix protein (M1) promotes export and inhibits import. Cell 1991;67:117-30.

14. Silver PA. How proteins enter the nucleus. Cell 1991;64:489-97.

15. Huang X, Liu T, Muller J, et al. Effect of influenza virus matrix protein and viral RNA on ribonucleoprotein formation and nuclear export. Virology 2001;287:405-16.

16. Ward AC, Castelli LA, Lucantoni AC, et al. Expression and analysis of the NS2 protein of influenza A virus. Arch Virol 1995;140: 2067-73.

17. Yasuda J, Nakada S, Kato A, et al. Molecular assembly of influenza virus: association of the NEP protein with virion matrix. Virology 1993;196:249-55.

18. Neumann G, Watanabe T, Ito $\mathrm{H}$, et al. Generation of influenza A viruses entirely from cloned cDNAs. Proc Natl Acad Sci USA 1999;96:9345-50.

19. Bucher DJ, Kharitonenkov IG, Zakomirdin $\mathrm{JA}$, et al. Incorporation of influenza virus M-protein into liposomes. J Virol 1980;36:586-90.

20. Enami M, Enami K. Influenza virus hemagglutinin and neuraminidase glycoproteins stimulate the membrane association of the matrix protein. J Virol 1996;70:6653-57.

21. Gregoriades A. Interaction of influenza M protein with viral lipid and phosphatidylcholine vesicles. J Virol 1980;36:470-9.

22. Lamb RA, Choppin PW. The structure and replication of influenza virus. Ann Rev Biochem 1983;52:467-506.

23. Lamb RA, Zebedee SL. Influenza virus M2 protein is an integral membrane protein expressed on the infected-cell surface. Cell 1985;40:627-33.

24. Robertson BH, Bennett JC, Compans RW. Selective dansylation of $\mathrm{M}$ protein within intact influenza virus. J Virol 1982;44:8716.

25. Ye Z, Pal R, Fox JW, Wagner RR. Functional and antigenic domains of the matrix (M1) protein of influenza virus. J Virol 1987; 61:239-46.

26. Gomez-Puertas, P, Albo C, Perez-pastrana $\mathrm{E}$, et al. Influenza virus matrix protein is the major driving force in virus budding. $\mathrm{J}$ Virol 2000;74:11538-47.

27. Watanabe K, Fuse T, Asano I, et al. Identification of Hsc70 as an influenza virus matrix protein (M1) binding factor in involved in the virus life cycle. FEBS Letters 2006;580:5785-90.

28. Elster C, Larsen K, Gagnon APJ, et al. Influenza virus M1 protein binds to RNA through its nuclear localization signal. J Gen Virol 1997;78:1589-96.

29. Wakefield L, Brownlee GG. RNA-binding properties of influenza A virus matrix protein M1. Nucleic Acid Res 1989;17:8569-80.

30. Ye Z, Baylor NW, Wagner RR. Transcription-inhibition and RNA-binding domains of influenza virus matrix protein mapped with anti-idiotype antibodies and synthetic peptides. J Virol 1989;63:3586-94.

31. Ye Z, Pal R, Fox JW, Wanger RR. Functional and antigenic domains of the matrix(M1) Protein of influenza virus. J Virol 1987;61:239-46.

32. Akarsu H, Burmeister WP, Petosa C, et al. Crystal structure of the M1 protein-binding domain of the influenza $\mathrm{A}$ virus nuclear export protein(NEP/NS2). EMB0 J 2003;22:4646-55.

33. Huang X, Liu T, Muller J, et al. Effect of influenza virus matrix protein and viral RNA on ribonucleoprotein formation and nuclear export. Virology 2001;287:405-16.

34. Hui EKW, Barman S, Yang TY, Nayak DP. Basic Residue of the Helix Six Domain of Influenza Virus M1 Involved in Nuclear Translocation of M1 Can Be Replaced by PTAP and YPDL Late Assembly Domain Motifs. J Virol 2003;77:7078-92.

35. Brown E, Liu H, Kit L, et al. Pattern of mutation in the genome of influenza $\mathrm{A}$ virus on adaptation to invreased virulence in the muse lung: identification functional themes. Proc Natl Acad Sci U S A 2001;98: $6883-8$

36. Govorkova EA, Gambaryan AS, Class EC, Smirnov YA. Amino acid Changes in the hemagglutinin and matrix proteins of influenza A (H2) viruses adapted to mice. Acta Virol 2000;44:241-8.

37. Smeenk CA, Brown EG. the influenza virus variant $\mathrm{A} / \mathrm{FM} / \mathrm{1} / 47-\mathrm{MA}$ possesses single amino acid replacement in the hemagglu- tinin, controlling virulence, and in the matrix protein, controlling virulence as well as growth. J Virol 1994;68:530-4.

38. Smeenk CA, Wright KE, Burns BF, et al. Mutation in the hemagglutinin and matrix genes of a virulent influenza virus variant, A/FM/1/47-MA. Control different stages in pathogenesis. Virus Res 1996;44:79-95.

39. Fan S, Deng G, Song J, et al . Two amino acid residues in the matrix protein $\mathrm{M} 1$ contribute to the virulence difference of $\mathrm{H} 5 \mathrm{~N} 1$ avian influenza viruses in mice. Virology 2009;384:28-32.

40. Furuse Y, Suzuki A, Kamigaki T, et al. Reversion of Influenza A (H3N2) from Amantadine-resistant to Amantadine-sensitive by Further Reassortment in Japan during the 2006-2007 Influenza Season. J Clin Microbiol 2009;47:841-4.

41. Simonsen L, Viboud C, Grenfell BT, et al. The genesis and spread of reassortment human influenza $\mathrm{A} / \mathrm{H} 3 \mathrm{~N} 2$ viruses conferring adamantane resistance. Mol Biol Evol 2007;24:1811-20.

42. Holmes EC, Ghedin E, Miller N, et al. Wholegenome analysis of human influenza A virus reveals multiple persistent lineages and reassortment among recent H3N2 viruses. Plos Biol 2005;3:e300.

43. Garcia-Robles I, Akarsy H, Muller CW, et al. Interaction of influenza virus proteins with nucleosomes. Virology 2005;332:32936.

44. Naffakh N, Tomoiu A, Rameix-Welti MA, van der Werf S. Host restriction of avian influenza viruses at the level of the ribonucleoproteins. Ann Rev Microbiol 2008;62:403-24.

45. Huang X, Liu T, Muller J, et al. Effect of influenza virus matrix protein and viral RNA on ribonucleoprotein formation and nuclear export. Virology 2001;287:405-16.

46. Takizawa N, Watanabe K, Nouno K, et al. Association of functional influenza viral proteins and RNAs with nuclear chromatin and sub-chromatin structure. Microb Infect 2006;8:823-33.

47. Reinhardt J, Wolff T. The influenza A virus M1 protein interacts with the cellular receptor of activated C kinase (RACK) 1 and can be phosphorylated by protein kinase C. Vet Microbiol 2000;74:87-100.

48. Pleschka S, Wolff T, Ehrhardt C, et al. Influenza virus propagation is impaired by inhibition of the Raf/MEK/ERK signaling cascade. Nat Cell Biol 2001;3:301-5. 